\title{
Turismo Comunitário e Gestão Participativa na RDS Estadual Ponta do Tubarão (RN): processose perspectivas
}

\section{Community tourism and Participative Management in RDS Ponta do Tubarão (RN, Brazil): processes and perspectives}

\author{
Iracy Wanderley Filha; Aída Gisella Veras Mazzolini; \\ Francisco Fransualdo de Azevedo
}

\section{RESUMO}

O desenvolvimento do turismo em áreas protegidas tem gerado discussões entre estudiosos do setor em relação ao seu planejamento, sustentabilidade e a viabilidade em conciliar os objetivos da conservação ambiental, da economia e da gestão comunitária. A Reserva de Desenvolvimento Sustentável Estadual Ponta do Tubarão (RDSEPT), localizada no litoral setentrional do estado do Rio Grande do Norte, foi a primeira Unidade de Conservação (UC) estadual criada por reivindicação da sociedade civil organizada que vive nessa área. Esse processo se deu em virtude das ameaças de degradação dos recursos naturais decorrentes, principalmente, da especulação imobiliária e da atividade de carcinicultura nos manguezais da região. Dentre as alternativas de uso sustentável do ambiente da RDSEPT, o turismo comunitário tem sido apontado pelos moradores locais, como uma prática capaz de gerar, simultaneamente, renda, oportunidade de trabalho e conservação ambiental. Nesse contexto, este artigo tem como objetivo analisar e compreender os processos participativos e perspectivas do desenvolvimento do turismo comunitário, na RDSEPT. A pesquisa tem abordagem qualitativa, natureza exploratório-descritiva, com adoção de coleta de dados secundários para o levantamento bibliográfico e documental, bem como a observação participante. Os resultados mostraram que a o turismo comunitário na Reserva está em processo de organização, sendo desenvolvida de forma incipiente, gerenciada por associação comunitária local, envolvendo também a participação do Grupo de Trabalho do Turismo e sem intervenções do setor público. A referida UC não possui, oficialmente implementado, um Plano de Manejo que contemple programas de uso público e de manejo do turismo. Esses fatores, associados à carência de investimentos públicos e privados em infraestrutura necessária ao turismo, podem ser responsáveis pelas dificuldades ao processo desenvolvimento da atividade na Reserva de Desenvolvimento Sustentável Estadual Ponta do Tubarão.

PALAVRAS-CHAVE: Turismo Comunitário; Participação; Unidades de Conservação. 


\section{ABSTRACT}

The tourism development in protected areas has been widely debated with regard to its planning, sustainability and feasibility to conciliate the aims of environmental conservation, business and community management. The Ponta do Tubarão State Sustainable Development Reserve (PTSSDR), located in the Rio Grande do Norte state northern coast, was the first Conservation Unit created by the claim of the local organized civil society. This process occurred due to the threats of degradation of natural resources, coming from real estate speculation and Shrimp farming activity in Mangroves of the region. Among the alternatives for a sustainable usage of RDSEPT environment, the community tourism has been pointed out by the naive residents as a practice with potential to provide income, job opportunities and environmental conservation. In this context, our goal is to analyze and understand the participatory processes and the perspectives of the community tourism in RDSEPT. This research has a qualitative approach, descriptive-exploratory nature, with adoption of secondary data collection for bibliographic and documental searching, as well as participant observation. The results showed that the community tourism in the Reserve is in process of organization, with incipient development, being managed by local associations, involving the participation PTSSDR Tourism Working Group, with no intervention from public department. The already-mentioned Conservation Unit does not have an official Management Plan, encompassing public programs and tourism management. These factors, together with the lack of public and private investments in infrastructure, may be the responsible for difficulties in the The Ponta do Tubarão State Sustainable Development Reserve activity developmental process.

KEYWORDS: Community Tourism; Participation; Protect Areas.

\section{Introdução}

As estratégias de proteção das Unidades de Conservação (UC) implicam na preservação dos seus sistemas naturais e culturais conciliada com práticas econômicas que atendam às necessidades das sociedades que vivem nesses espaços e no seu entorno. Nesse prisma de abordagem, o turismo tem sido apontado como uma prática capaz de sustentar essas áreas naturais protegidas. "Por isso, o uso turístico de toda a paisagem em uma área natural protegida envolve a gestão de recursos comuns e do espaço, considerando o equilíbrio natural e social do ambiente analisado" (PAVON et al., p.26, 2015).

No entanto, precisa-se atentar para o fato de que a atividade turística, além de representar um incremento enquanto atividade econômica para o destino, também gera impactos que comprometem a manutenção de recursos naturais e o desenvolvimento comunitário. A apropriação de terras para a criação de parques e outras unidades de conservação, assim como a escolha de locais para a instalação de grandes complexos hoteleiros está frequentemente associada a riscos e injustiças sociais (EMBRATUR/IEB, 2001). Com isso, Irvin (2000) inferiu que, geralmente, as comunidades autóctones receptoras do fenômeno turístico, não usufruem dos benefícios do crescimento do turismo, visto que há pouco comprometimento com 0 desenvolvimento local. 
No contexto das políticas públicas de turismo, o governo brasileiro, no Plano Nacional de Turismo (PNT 2003-2007) orienta para o planejamento e gestão integrada com os governos estaduais, propondo ações como incentivos financeiros e fiscais, promoção dos destinos e construção de infraestrutura que articuladas, constroem um ambiente propício para investimentos privados no setor de turismo (BRASIL, 2003). Paradoxalmente, essas orientações evidenciam 0 foco econômico e estrutural dessa política e a dificuldade de inclusão das populações tradicionais na atividade turística.

Em consequência disso, frequentemente no Brasil e no mundo, a maioria dos críticos e estudiosos dessa área tem associado o desenvolvimento do turismo à especulação imobiliária e a grilagem de terras que levam a expulsão de comunidades, a descaracterização das culturas locais e consequente desestruturação social, o aumento do custo de vida, a concentração de renda e a degradação ambiental.

Diante dessa situação, ao longo das últimas décadas muitos países firmaram uma série de protocolos com o intuito de minimizar os efeitos negativos do turismo, buscaram estabelecer uma correlação de força menos desigual entre o multisetor turístico e os atores envolvidos nele e no seu entorno (político, econômico, sociocultural e ecológico), e pensar esse fenômeno sustentável, conforme balizam as declarações de Otavalo e de San José (SANTANA TALAVERA, 1990, 2009; JAFARI, 2001; OIT, 2001, 2003; BOISSEVAIN, 2007; BARRETTO, 2009; PINTO; CASTRO, 2013).

$\mathrm{Na}$ arena das organizações da sociedade civil do Brasil empenhadas na crítica ao modelo do turismo de massa e a proposição de alternativas, destacam-se o Fórum em Defesa da Zona Costeira no Ceará (2004), a Iniciativa de Gênero para Monitoramento das Instituições Financeiras Multilaterais, e o Grupo de Trabalho de Turismo FBOMS/REDE BRASIL (2005). Em âmbito internacional assinala-se o Fórum Global de Turismo, sobretudo a partir da construção das reflexões e articulações da temática de turismo no Fórum Social Mundial da Índia (2004) e Porto Alegre (RS) (2005) e das redes que buscam a construção do Turismo Comunitário (TC), a exemplo da Rede de Turismo Comunitário da América Latina (REDTURS).

Nessa órbita de movimentação social, torna-se perceptível o aumento da capacidade das lideranças comunitárias em questionar e compreender os impactos do modelo de turismo em curso, bem como a articulação de redes nacionais e internacionais, a exemplo da Rede Brasileira de Turismo Solidário - TURISOL e da REDTURS que intencionam a construção de uma proposta de turismo comunitário, pautada no envolvimento e na ação das comunidades costeiras, na perspectiva de contribuir na melhoria da qualidade de vida das populações e para a justiça socioambiental, por meio da integração entre economia solidária e conservação ambiental.

Partindo-se desse enfoque, o turismo comunitário apresenta uma perspectiva de incorporação de atitudes mais responsáveis em relação às suas modalidades massivas, valorizando as práticas voltadas para a economia solidária, a autogestão da cadeia produtiva, 0 associativismo/cooperativismo e a valorização das culturas locais, enfatizando o protagonismo das comunidades locais (BRASIL, 2008a). Nas 
perspectivas teóricas acerca desse tema, ainda não há um consenso na definição de turismo comunitário. Para o Ministério do Turismo- MTur essa falta de consenso resulta da heterogeneidade das experiências, da origem do território e da perspectiva política da organização não governamental, responsável por organizar e viabilizar a experiência.

Todavia, o MTur traça como princípios comuns: a autogestão; o associativismo/cooperativismo; a democratização de oportunidades e benefícios; a centralidade da colaboração, parceria e participação; a valorização da cultura local e, principalmente, o protagonismo das comunidades locais na gestão da atividade e/ou na oferta de bens e serviços turísticos, visando à apropriação por parte destas dos benefícios advindos do desenvolvimento da atividade turística (BRASIL, 2010). Com isso, percebe-se o início da influência das experiências do TC na formulação da política pública de turismo. Acrescido a essa, existem outras concepções conceituais à luz do entendimento de instituições e teóricos (Quadro 1):

Quadro 1: Definições de turismo comunitário.

Table 1: Definitions of community tourism.

\begin{tabular}{|c|c|}
\hline Instituição/Associação/Autor & Definição \\
\hline $\begin{array}{c}\text { World Trade Organization } \\
\text { (WTO) }\end{array}$ & $\begin{array}{l}\text { "Uma interação visitante/anfitrião, cuja participação é } \\
\text { significativa para ambos e gera benefícios econômicos } \\
\text { e de preservação para as comunidades e o meio } \\
\text { ambiente local". UNCTAD/WTO }(2005, \text { p. } 27)\end{array}$ \\
\hline $\begin{array}{l}\text { World Wildlife Fund } \\
\text { (WWF-Brasil) }\end{array}$ & $\begin{array}{l}\text { "Turismo realizado em áreas naturais, determinado e } \\
\text { controlado pelas comunidades locais, gera benefícios } \\
\text { predominantemente para estas e para as áreas } \\
\text { relevantes para a conservação da biodiversidade". } \\
\text { WWF }(2003, \text { p. } 23)\end{array}$ \\
\hline $\begin{array}{l}\text { Ministério do Turismo } \\
\text { (MTur-Brasil) }\end{array}$ & $\begin{array}{l}\text { "O turismo de base comunitária é compreendido como } \\
\text { um modelo de desenvolvimento turístico, orientado } \\
\text { pelos princípios da economia solidária, associativismo, } \\
\text { valorização da cultura local, e, principalmente, } \\
\text { protagonizado pelas comunidades locais, visando à } \\
\text { apropriação por parte dessas dos benefícios advindos } \\
\text { da atividade turística" (MTur, 2008, p.1). }\end{array}$ \\
\hline $\begin{array}{l}\text { Rede Cearense de Turismo } \\
\text { Comunitário - TUCUM }\end{array}$ & $\begin{array}{l}\text { "Turismo Comunitário é uma oportunidade para } \\
\text { aperfeiçoar a organização comunitária, o } \\
\text { desenvolvimento local e a cogestão para preservar o } \\
\text { patrimônio natura, cultural e as formas de vida } \\
\text { tradicionais das comunidades e do seu território". } \\
\text { (http://prainhadocantoverde.org) }\end{array}$ \\
\hline Coriolano & $\begin{array}{l}\text { "O turismo comunitário é aquele em que as } \\
\text { comunidades de forma associativa organizam arranjos } \\
\text { produtivos locais, possuindo o controle efetivo das } \\
\text { terras e das atividades econômicas associadas às } \\
\text { exploração do turismo" (CORIOLANO, 2009. P.282) }\end{array}$ \\
\hline Irving & $\begin{array}{l}\text { "Aquele tipo de turismo que, em tese, favorece coesão } \\
\text { e o laço social e o sentido coletivo da vida em } \\
\text { sociedade, e que por esta via, promove a qualidade de } \\
\text { vida, o sentido da inclusão, a valorização da cultura } \\
\text { local e o sentimento de pertencimento". (IRVING, } \\
\text { 2009. P.111) }\end{array}$ \\
\hline
\end{tabular}

Fonte: Burgos e Mertens (2015).

Source: Burgos and Mertens (2015). 
Acerca da necessidade de compreender os processos e perspectivas do desenvolvimento do turismo comunitário em unidades de conservação, este artigo objetiva analisar e compreender esse fenômeno, tendo como recorte espacial a Reserva de Desenvolvimento Sustentável Estadual Ponta do Turbarão (RDSEPT), localizada no litoral setentrional do Estado do Rio Grande do Norte/Brasil. Para alcance desse objetivo utilizou-se como aporte metodológico uma pesquisa de abordagem qualitativa, de natureza exploratório-descritiva adotando-se a coleta de dados secundários para 0 desenvolvimento da pesquisa bibliográfica e documental e a observação participante para ampliar o acervo de informações sobre o tema deste estudo.

\title{
Processos Participativos para o Turismo Comunitário Na RDSEPT
}

O território brasileiro é composto por um rico e diverso potencial natural e sociocultural, de inquestionável relevância para a vida no planeta. Diante disso, surge a necessidade de se criar estratégias, do ponto de vista da norma e do envolvimento da sociedade, que garantam a proteção desses sistemas espaciais. Tendo em vista esses fatores, o governo brasileiro criou por meio da Lei Federal 9.985 de 2000, o Sistema Nacional de Unidades de Conservação da Natureza (SNUC). Esse instrumento legal define como conceito de unidade de conservação:

\begin{abstract}
espaço territorial e seus recursos ambientais, incluindo as águas jurisdicionais, com características naturais relevantes, legalmente instituído pelo Poder Público, com objetivos de conservação e limites definidos, sob regime especial de administração, ao qual se aplicam garantias adequadas de proteção (BRASIL, 2000).
\end{abstract}

O SNUC deixa claro que o objetivo da conservação dos recursos ambientais presentes no território, legalmente instituídos e legitimados pelo poder público, necessitam de garantias de proteção. Essa Lei ainda detalha a conservação da natureza como sendo:

o manejo do uso humano da natureza, compreendendo a preservação, a manutenção, a utilização sustentável, a restauração e a recuperação do ambiente natural, para que possa produzir o maior benefício, em bases sustentáveis, às atuais gerações, mantendo seu potencial de satisfazer as necessidades e aspirações das gerações futuras, e garantindo a sobrevivência dos seres vivos em geral (BRASIL, 2000).

No mundo contemporâneo, a criação de áreas protegidas se dá sob o fundamento do paradigma da sustentabilidade. Difundido mundialmente, a 
sustentabilidade é algo a ser alcançada por todos os países, segundo as cartilhas da ONU e das cúpulas mundiais que tratam do tema. Na medida em que os países desenvolvem ações em prol desse fim, mantém uma boa imagem perante as demais nações, e conseguem altos recursos financeiros para diversos programas (GUERRA; COELHO, 2009).

Um dos maiores avanços do SNUC foi a definição pormenorizada de cada categoria de Unidade de Conservação, apresentando uma definição para cada uma delas. Trata-se de sistematizar todos os princípios, fundamentos, categorias, diretrizes, e demais aspectos relacionados ao planejamento e gestão dessas áreas (MERCADANTE, 2007). O SNUC instituiu, em seu art. $7^{\circ}$, dois grupos de UC's: Unidades de Proteção Integral e Unidades de Uso Sustentável, subdivididos em 12 (doze) categorias específicas (Quadro 2).

Quadro 2: Grupos de Unidades de Conservação e suas categorias.

Table 2: Groups of Protect Areas and their categories.

\begin{tabular}{cc}
\hline Unidades de Proteção Integral & Unidades de Uso Sustentável \\
\hline Estação Ecológica & Área de Proteção Ambiental \\
Monumento Natural & Área de Relevante Interesse Ecológico \\
Parque Nacional & Floresta Nacional \\
Refúgio de Vida Silvestre & Reserva de Desenvolvimento Sustentável \\
Reserva Biológica & Reserva de Fauna \\
& Reserva Extrativista \\
& Reserva Particular do Patrimônio Natural \\
\hline
\end{tabular}

Fonte: Brasil (2000).

Source: Brasil (2000).

Sendo o cerne das discussões traçadas neste trabalho, é importante destacar que o SNUC define Reserva de Desenvolvimento Sustentável (RDS) como área natural que abriga populações tradicionais, cuja existência se baseia em sistemas sustentáveis de exploração dos recursos ecológicos, desenvolvidos por diversas gerações, adaptados às condições naturais locais e que desempenham um papel básico na proteção da natureza e na manutenção da diversidade biológica (BRASIL, 2000).

Um dos pontos de maior importância para o êxito de uma Unidade de Conservação é a gestão participativa. O SNUC, em seu Art. 50, parágrafo 20 , estabelece como uma das diretrizes principais "assegurar a participação efetiva das populações locais na criação, implantação e gestão das unidades de conservação". Dessa forma, é fundamental que as comunidades residentes e do entorno dessas áreas protegidas, participem de todos os processos de definição de usos e ocupações dessas UCs. O entendimento dos processos de participação da sociedade civil e sua presença na construção e execução de políticas públicas ${ }^{1}$ têm íntima relação com a concepção de democratização na sociedade brasileira e de suas lutas por acesso à cidadania e direitos sociais (MOTTA; GOHN, 2007; BEZERRA; 2010).

Nas reflexões acerca dos sentidos de participação da sociedade nas decisões de interesse da coletividade, Bordenave (1994, p.25) diz que "uma 
sociedade participativa seria, então, aquela em que todos os cidadãos têm parte na produção, gerência e usufruto dos bens da sociedade de maneira equitativa". Nesse processo há uma relação com a cidadania, o protagonismo comunitário, o sentido de responsabilidade e de pertencimento a um grupo, classe ou comunidade. Igualmente, isso também pode ser percebido nas contribuições de Demo (2001, p.18):

\begin{abstract}
Participação é conquista para significar que é um processo, no sentido legítimo do termo: infindável, em constante vir a ser, sempre se fazendo. Assim, participação é em essência autopromoção e existe enquanto conquista processual. Não existe participação suficiente, nem acabada.
\end{abstract}

A participação da sociedade no exercício do poder político, de acordo com Cogo e Dallabrida (2013, p.3) "é o que oportuniza a prática da democracia, entendida esta como a liberdade de exercício dos direitos civis e políticos dos cidadãos, vistos estes dentro da ótica jusnaturalista".

A importância da participação coletiva e consciente daqueles que compõem uma unidade social, tem a ver com a vontade de participar, causada por diversos fatores que vão desde a insatisfação política até a certeza de que a participação comunitária plena pode construir as bases para o empoderamento. É possível afirmar que isso acontece quando todos os envolvidos tomam consciência de seu poder de influência, no cenário ao qual estão inseridos e, assumem a responsabilidade de exercê-lo de forma dinâmica nas questões que surgirem e que lhes são atribuídas.

Como explica (MAGALHÃES et al, 2010, p.189) "a gestão participativa corresponde a um conjunto de princípios e processos que defendem e permitem o envolvimento regular e significativo dos colaboradores na tomada de decisão". Sendo assim, a participação efetiva e competente dos indivíduos na dimensão da coletividade, se fortalece na resolução de problemas, possibilitando fazer intervenções participativas e garantindo resultados positivos.

\title{
Unidade de análise da pesquisa
}

No ano de 2003, foi criada pelo governo do Estado do Rio Grande do Norte, a Reserva de Desenvolvimento Sustentável Estadual Ponta do Tubarão (RDSEPT) por meio da Lei no 8.349. (Figura 1). Configura-se em uma resposta do Estado à solicitação das comunidades da região para criação de uma Unidade de Conservação que tanto protegesse os recursos naturais da região, quanto assegurasse o uso do espaço e de seus recursos naturais e a atividade tradicional das comunidades moradoras da Reserva.

Com 12.960 mil hectares de área protegida, a RDSEPT está localizada nos municípios de Macau e Guamaré, litoral setentrional do Estado. Abrange uma região costeira de ilhas-barreiras, composta pelo sistema estuarino do Rio Tubarão, com a presença de extensos manguezais, restingas, dunas móveis de rara beleza cênica, lagoas de água doce e ainda um espaço representativo do bioma Caatinga. Essa Reserva abriga uma população de pescadores e agricultores com atividades 
baseadas em um sistema sustentável de exploração de recursos naturais, desenvolvidas tradicionalmente ao longo de gerações e adaptadas às condições ambientais locais (Figura 2).

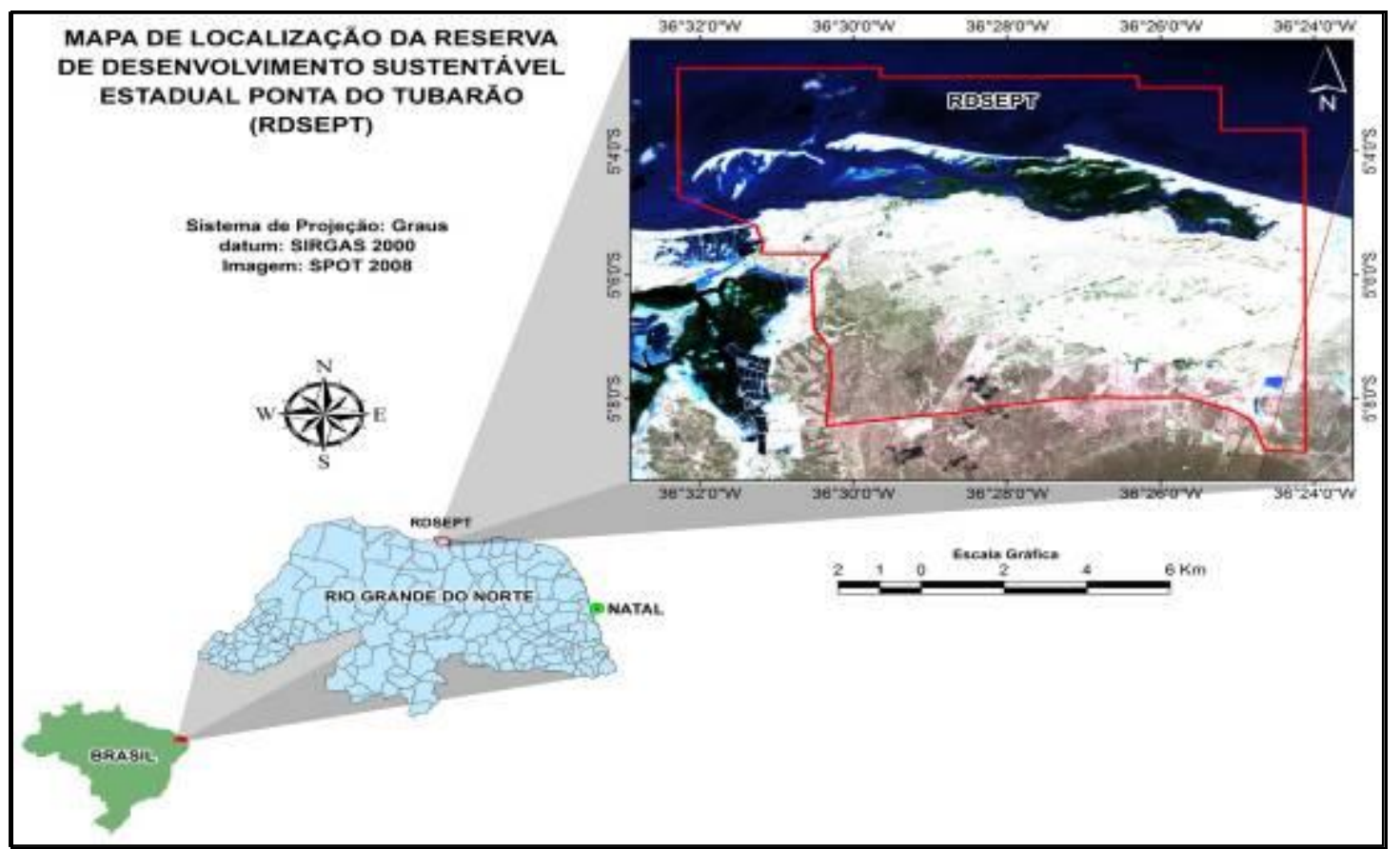

Figura 1: Mapa de localização da RDS Estadual Ponta do Tubarão.

Figure 1: Map of location of Sustainable Development State Reserve Ponta do Tubarão.

Fonte: Elaborado pelo autor (2015).

Source: Prepared by the author (2015).

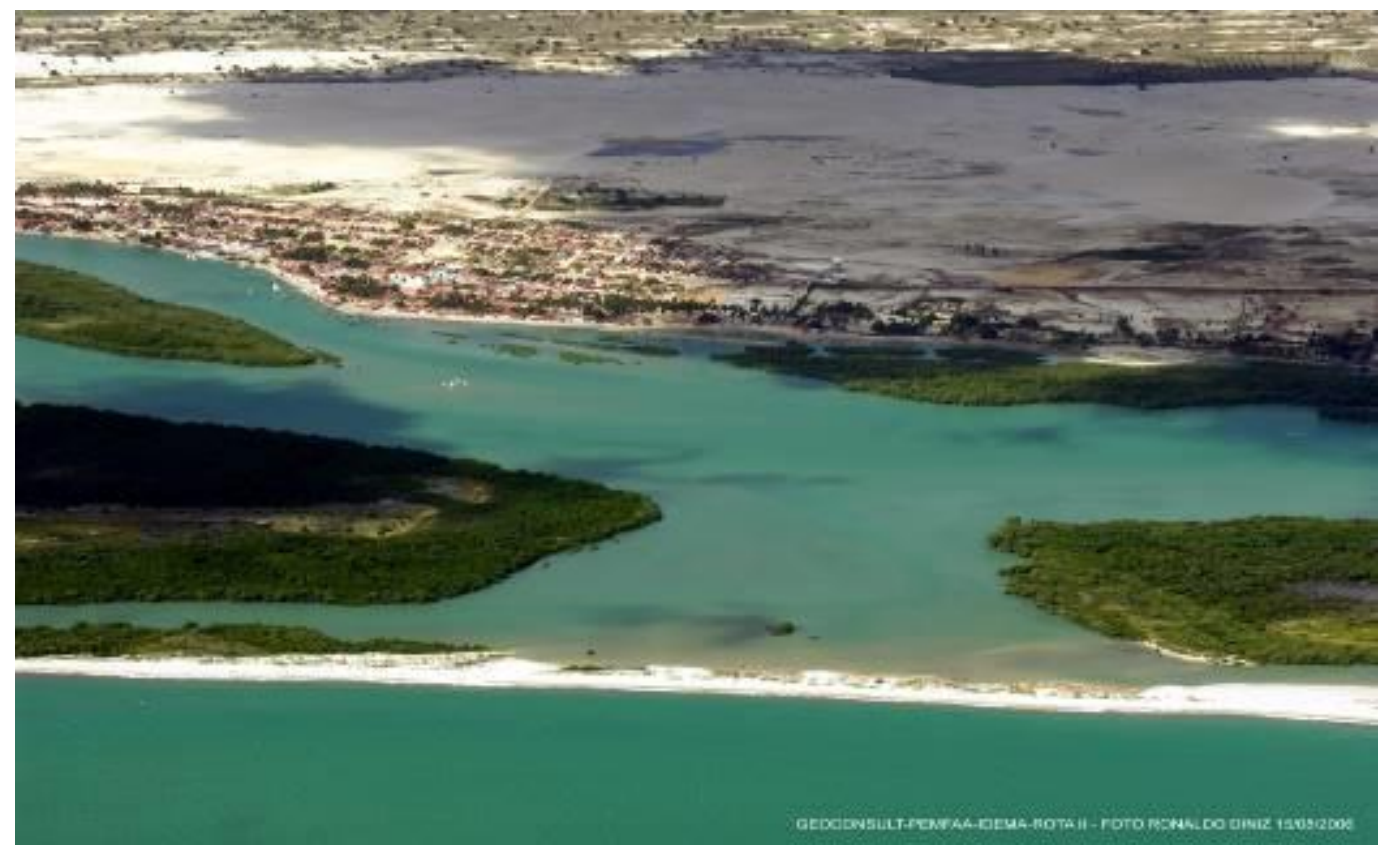

Figura 2: Sistema Ecológico da RDSEPT.

Figure 2: Ecological System of the RDSEPT.

Fonte: IDEMA (2009).

Source: IDEMA (2009). 
Espaços com esse conteúdo paisagístico, tem se constituído atrativos para a rápida implantação da atividade turística. Especialmente em regiões menos favorecidas, sob a ótica socioeconômica, o fenômeno turístico não tem ocorrido a favor das populações locais, que ficam normalmente distantes das benesses de seu desenvolvimento. $O$ interesse na minimização dos efeitos nocivos do turismo convencional sobre as populações locais estimulara uma nova forma de desenvolvimento dessa atividade que coloca a população local no centro do planejamento e promova práticas mais justas e sustentáveis. Junto a esses fatores, o crescimento da consciência crítica por parte dos turistas, unido à preocupação com a manutenção dos sistemas ecológicos e socioculturais, abriu espaço para atividades turísticas de cunho social e ambiental, incentivando a necessidade de aproximação deste fenômeno dos anseios da comunidade (HIWASAKI, 2006; BURSZTYN; BARTHOLO, 2012).

Como previsto pelo SNUC, numa RDS o objetivo é promover o desenvolvimento sustentável a partir dos recursos naturais seguindo-se princípios e práticas de conservação da natureza. Nesse contexto, o turismo nessas áreas protegidas representa uma alternativa aos possíveis impactos negativos da ação humana. Parece claro afirmar que o desenvolvimento sustentável é a justificativa para a busca de novos caminhos/alternativas por parte dos indivíduos que se entendem responsáveis por esses espaços. Para Ansarah (2001, p. 30):

O estudo do turismo deve ser direcionado para 0 desenvolvimento sustentável, conceito essencial para alcançar metas de desenvolvimento sem esgotar os recursos naturais e culturais nem deteriorar 0 meio ambiente, entende-se que a proteção do meio ambiente e o êxito do desenvolvimento turístico são inseparáveis.

O despertar para a necessidade de se proteger aquela região ocorreu depois que empreendedores italianos tentaram explorar a área para a construção de um complexo turístico na comunidade de Diogo Lopes em 1995, e em um segundo momento, em 2000, a tentativa de ocupação do manguezal com a construção de viveiros para produção de camarão. Ocorridos esses fatos, as comunidades da RDSEPT buscaram apoio do poder público para a proteção do manguezal e dos recursos pesqueiros da região, os quais são a principal fonte de sua subsistência.

A estrutura organizacional da RDSEPT consiste em um Conselho Gestor $^{2}$ composto de representações da sociedade civil, instituições públicas e setor produtivo. Para dinamizar as ações demandadas pelo processo de superação dos desafios para o desenvolvimento da RDSEPT, o referido conselho criou quatro Grupos de Trabalho (GTs): GT Turismo; GT Pesca; GT Uso e ocupação do Solo e GT Monitoramento que, apesar de serem autônomos e responsáveis pela sua própria institucionalidade, possuem uma relação estreita com o Conselho Gestor da RDSEPT.

Pelos relatos das representações sociais desta RDSEPT, fruto da observação participante in loco, desde o início das dinamizações o turismo 
sempre foi considerado uma atividade econômica potencial a ser desenvolvida na Reserva, de maneira complementar a pesca e não substitutiva, criando assim novas oportunidades para todos os moradores, incluindo os pescadores e seus familiares. A proposta do GT era tanto discutir a forma de turismo que se desejava para a Reserva, como a maneira mais adequada de implantá-lo, de acordo com a realidade de uma "Reserva de Desenvolvimento Sustentável" e das comunidades da Ponta do Tubarão.

Diante dessa necessidade, foram realizados: seminários e oficinas, bem como visita do GT a Prainha do Canto Verde no município de Beberibe (CE). Além destas iniciativas buscou-se apoio do Instituto Terramar (CE), para a realização das oficinas de trabalho, em vista da larga experiência da organização não governamental cearense na implantação de turismo de base comunitária junto a comunidades da Zona Costeira do Ceará.

O GT de Turismo é formado por moradores da Reserva interessados nas várias atividades relacionadas a esta atividade como hospedagem, alimentação, passeios, realização de eventos e artesanato. Uma das principais atividades do GT foi definir os princípios fundamentais que deveriam embasar qualquer atividade relacionada ao turismo na RDSEPT. Após intenso período de discussão participativa foram definidos doze princípios como prioritários (Quadro 3).

Quadro 3: Princípios do GT de Turismo da RDSEPT.

Table 3: WG of Principles of Tourism in RDSEPT.

1. Capacitação adequada dos empreendedores locais e todos os envolvidos na cadeia produtiva do turismo;

2. Adequação da atividade turística ao programa de educação ambiental da RDSEPT, voltado para moradores e visitantes da RDSEPT;

3. Regulamentação das atividades dos empreendedores e visitantes, de acordo com as normas e regras pré-estabelecidas na RDSEPT;

4. Implantação da infraestrutura necessária para saneamento básico (abastecimento de água, esgotamento sanitário, tratamento de resíduos sólidos) e transporte;

5. Prioridade aos empreendedores locais (reserva de quotas, por exemplo);

6. Assegurar a qualidade de vida dos moradores;

7. Reverter parte dos recursos advindos da atividade turística para um fundo de desenvolvimento para o turismo;

8. Reverter os lucros advindos da atividade turística para benefícios sociais na RDSEPT;

9. Valorização do artesanato e eventos culturais locais, fomentando a identidade da RDSEPT;

10. Garantia da sustentabilidade social, ambiental, cultural e econômica;

11. Garantia dos espaços comuns ao uso coletivo;

12. Inclusão dos pescadores na atividade turística.

Fonte: IDEMA (2007), adaptado pelo autor.

Source: IDEMA (2017), Prepared by the author (2015).

A partir destes princípios, os moradores da Reserva, participantes do Grupo de Turismo, votaram oficialmente que o segmento de turismo nesta Unidade de Conservação deveria ser de base comunitária, privilegiando os empreendedores locais e gerando benefícios sociais para toda a UC. Mediante a gestão sob controle das comunidades da RDS Ponta do Tubarão, o turismo foi considerado como uma atividade complementar. Por isso, deve ser praticada de maneira integrada às tradicionais formas de 
trabalho desenvolvidas pela comunidade e que, por sua vez, pode ser também um meio para alcançar objetivos sociais e ambientais (IDEMA, 2007).

Ainda do ponto de vista da gestão, a RDS Estadual Ponta do Tubarão é marcada pela participação das comunidades envolvidas nos processos de criação, implantação e processos de desenvolvimento que são assegurados pela legislação superior (Lei Federal no 9.985/2000). Na verdade, a existência do Conselho Gestor, pela referida normativa, ocorre para garantir a participação da sociedade nas decisões de interesse coletivo. Esse processo ocorre por meio de atores sociais provocando o fortalecimento da democracia. "Nesse contexto, o desenvolvimento se constrói a partir do protagonismo real, legítimo de cada indivíduo" (AZEVEDO, 2008, p. 5).

No caso do GT de Turismo da RDSEPT, as lideranças locais desse grupo temático construíram, participando e/ou organizando seminários de reflexão a respeito do turismo comunitário, envolvendo as comunidades que pertencem à Reserva, além de pesquisadores, jornalistas, estudantes, técnicos, políticos, ambientalistas e outros.

Percebe-se, então, que os GTs são espaços de discussão criados para que os segmentos da sociedade civil, em conjunto com os demais atores atuantes, pudessem assegurar a solução dos problemas enfrentados pela Reserva. Essa, dentre outras ações, é uma das formas de garantir a efetiva participação dos envolvidos nos assuntos de interesses da comunidade (OLIVEIRA, 2008).

Em 2004, foi realizado o I Seminário de Turismo Sustentável da RDS Estadual Ponta do Tubarão com objetivo de apresentar uma série de informações e experiências a respeito da atividade turística para subsidiar as comunidades da RDS no processo de decisão sobre a forma de turismo a ser implantado na RDS, como parte das estratégias de desenvolvimento sustentável territorial/local.

Torna-se evidente, portanto, que o processo de criação da RDSEPT, como também a idealização da prática do turismo, teve como protagonista a população autóctone. Este fato foi possibilitado, dentre outras coisas, pelos processos de educação ambiental, ainda em fase inicial, que propiciaram a ação participativa consciente e a ressignificação do sentimento de pertencimento ao lugar. Assim, empiricizando a fala de Santos (1994, p. 29) quando este afirma que, para que uma sociedade local incorpore os vetores verticais sem recusar sua participação no mundo, esta deve "descobrir e por em prática novas racionalidades em outros níveis e regulações mais consentâneas com a ordem desejada pelos homens, lá onde eles vivem".

\section{As perspectivas relativas ao Turismo Comunitário na RDSEPT}

Pelos princípios descritos no Quadro 3, torna-se possível concluir sobre as perspectivas da sociedade civil da RDSEPT com relação à implementação do turismo comunitário nessa unidade de conservação. Por essa abordagem percebe-se que os agentes sociais da UC apontam o fenômeno como um vetor que contribui para a melhoria do nível e da 
qualidade de vida da população, bem como para a prosperidade dos microempreendimentos e economia local. Ainda neste contexto, o modelo de turismo em questão aparece como potencializador da conservação dos aspectos culturais da comunidade autóctone, preservando e resgatando a autenticidade cultural dos moradores dessa área protegida. Sobre esse assunto, Max-Neef (2008), afirma que [...] "o elemento fundamental para a vitalidade das comunidades é a diversidade". Logo, o turismo comunitário pode ser visto como o "meio" para alcançar a conservação da diversidade dos modos de vida das comunidades e das identidades locais.

No princípio 2 que recomenda a adequação da atividade turística ao programa de educação ambiental da RDSEPT, voltado para moradores e visitantes da UC, se constitui numa nítida preocupação com a preservação dos sistemas naturais e sua fundamental importância enquanto objeto de consumo da atividade turística. A dimensão ambiental é recorrente nas concepções teóricas e institucionais sobre o turismo comunitário no quadro 1 enquanto referência conceitual para este texto. Além disso, as propostas contemporâneas de desenvolvimento do turismo em bases sustentáveis requerem o peso da dimensão ambiental incluso nesse processo.

No tocante ao desenvolvimento social das comunidades locais fica evidenciado nos princípios em discussão, o interesse que fenômeno turístico proporcione a melhoria dos serviços prestados por meio da qualificação dos empreendedores locais, melhoria da gestão dos negócios comunitários, fortalecimento da governança local, implantação de processos de monitoramento do turismo e, principalmente, questões relativas ao acesso ao mercado e comercialização desse produto turístico. São inúmeras as vantagens socioeconômicas e culturais que o Turismo Comunitário pode proporcionar a todos os agentes econômicos envolvidos. No entanto, Bursztyn e Bartholo (2012, p.98) atentam para o fato de que:

A falta de uma estratégia de inserção dos projetos no mercado turístico é tida como a principal causa de mortalidade das iniciativas após o término do período de apoio financeiro externo (sejam de agências internacionais para o desenvolvimento, ONGs nacionais e internacionais ou governos locais) que a maioria desses projetos recebe para desenvolver suas atividades.

Essa afirmativa alerta para a importância da atuação institucional frente ao planejamento turístico de segmento comunitário tendo em vista 0 sucesso da atividade e os interesses dos agentes envolvidos na dinâmica da atividade. O Estado enquanto agente regulador assume um papel de extrema relevância, na medida em que a sociedade se oriente para 0 desenvolvimento sustentável, o crescimento econômico e a igualdade social. No entanto, o Estado sozinho não é capaz de garantir o êxito dos princípios e objetivos propostos que constituem o TC. A infraestrutura necessária ao desenvolvimento do turismo necessita de investimentos públicos em educação, formação de recursos humanos e pesquisa, saúde, saneamento básico, segurança, transportes e outros (BUARQUE, 2008). 
É lícito afirmar que a cooperação entre o Estado e os demais setores da cadeia produtiva do turismo é fundamental para se constituir em uma necessidade para o desenvolvimento sustentável desse fenômeno. A importância da participação da sociedade na construção conjunta de planejamento e gestão, prevista na estrutura do TC, representa uma estratégia que pode garantir a redução de riscos em prevalecer interesses individuais/privados em detrimento dos múltiplos agentes do território. A dimensão humana do desenvolvimento está fundamentalmente na valorização das pessoas em sua plenitude, que supõe crescimento econômico não como fim, mas como meio de reduzir as privações e as aflições humanas (TORRAS, 1995).

O acesso ao mercado tem imposto certas dificuldades visto que, provavelmente, do ponto de vista econômico e mercadológico, os destinos que oferecem uma experiência em turismo comunitário, ainda não são considerados sucessos de venda e consumo nos cenários nacional e internacional. Em países da União Europeia (UE), nos Estados Unidos da América (EUA), bem como no Mercado Comum do Sul (MERCOSUL) tem se observado diversas iniciativas de turismo que tem no cerne das suas preocupações o desenvolvimento de políticas e estratégias de planejamento que regulamentem a sua prática de forma sustentável.

No Brasil, a resistência de comunidades locais ao turismo expropriador de terras no litoral nordestino despertou a atenção do Ministério do Turismo (MTur) para a criação de instrumentos que orientem a prática do Turismo que, auxiliado por organizações não governamentais (ONGs) e universidades descobrem formas de articulação com o mercado e de inclusão social. Nota-se que a expansão de redes do turismo comunitário em nível local, regional e global pode proporcionar a expansão do fenômeno como contraponto ao turismo convencional ou turismo de massa. Esse pode ser um grande desafio para as demais práticas turísticas em curso no Brasil, na busca de soluções para a melhoria da qualidade de vida, por meio do engajamento e a autonomia para o desenvolvimento sustentável.

\section{Considerações Finais}

A prática do turismo comunitário em uma área protegida requer regulamentação da atividade compatibilizada com a preservação dos recursos ambientais, pois envolve a presença de visitantes, visitados, profissionais da atividade turística e gestores ambientais. A ânsia por consolidar o turismo comunitário como uma forma de organização do turismo economicamente viável na RDSEPT direcionou as ações de promoção e divulgação da atividade ao mercado convencional do turismo de massa.

Embora a RDS Ponta do Tubarão constitua uma unidade de conservação com grande potencialidade para o desenvolvimento do turismo comunitário, muitas questões ainda devem ser planejadas para 0 afloramento efetivo da atividade na região.

A atividade turística desenvolvida na Reserva é totalmente gerenciada por associação comunitária local, sem maiores intervenções do setor público. Contudo, embora a RDSEPT não possua plano de manejo ${ }^{3}$ 
devidamente implementado, o turismo comunitário que vem sendo desenvolvido na região é considerado satisfatório. A referida UC ainda carece de investimentos públicos e privados, visando melhorar a qualidade de vida das comunidades tradicionais.

Dentro da visão da sustentabilidade, o GT de Turismo da RDSEPT possui algumas ações consolidadas, no entanto, para implementar outras existe a necessidade de buscar parcerias para financiamentos de projetos, bem como articulação com políticas públicas estaduais e municipais de turismo.

Dentre as tantas conquistas da Reserva, destaca-se a ampliação da participação através da criação de Grupos de Trabalhos temáticos que asseguram o envolvimento de pessoas que nem sempre estão diretamente ligadas ao Conselho Gestor, mas que podem contribuir significativamente com o planejamento e a gestão da Reserva.

No entanto, há muito o que ser feito para que o Turismo Comunitário realize todo o seu potencial em prol do desenvolvimento social das comunidades locais, como: melhoria dos serviços prestados por meio da qualificação dos empreendedores locais, melhoria da gestão dos negócios comunitários, fortalecimento da governança local, implantação de processos de monitoramento do turismo e, principalmente, questões relativas ao acesso ao mercado e comercialização são alguns dos obstáculos que devem ser superados.

Concluiu-se que a promoção do turismo comunitário em Unidades de Conservação requer participação dos dois atores principais, poder público e comunidade local, de forma contínua e pautada nos interesses da comunidade receptora, que é o principal executor da atividade turística.

\section{Referências}

ANSARAH, M.G.R. Turismo. Como aprender, como ensinar. São Paulo: Editora SENAC, 406 p., 2001.

AZEVEDO, F.F. Desenvolvimento local e capital social: uma abordagem teórica. Revista GEONORDESTE. v. 1, pp. 87-105, 2008.

BARRETTO, M. Turismo y Cultura. Relaciones, Contradicciones y Expectativas. EI Sauzal: Pasos, 2009.

BEZERRA, J. C. P. Direito e Etnoconservação: Estudo da Participação na gestão ambiental da RDS Estadual Ponta do Tubarão-RN. Dissertação de Mestrado, Universidade Federal do Rio Grande do Norte, Natal, RN, Brasil 2010.

BOISSEVAIN, J. Confrontando la Industria Turística en Malta. In: LAGUNAS, D. (Org.). Antropología y Turismo. Claves Culturales y Disciplinares. México D. C.: Plaza y Valdés, pp. 73-90, 2007.

BRASIL. MMA. Sistema Nacional de Unidades de Conservação da Natureza - SNUC: a lei n 9.985, de 18 de julho de 2000. Brasilia: MMA/SBF, 2000. 
BRASIL. Ministério do Turismo. Ecoturismo: Orientações Básicas. Brasilia, 2008a.

BORDENAVE, J.R. Díaz. O que é participação. 8 ed. São Paulo: Brasiliense, 1994 (Coleção Primeiros Passos).

BUARQUE, S.C. Construindo o desenvolvimento local sustentável: metodologia de planejamento. 4. ed. Rio de Janeiro: Garamond, 2008.

BURGOS, A.; MERTENS, F. Os desafios do turismo no contexto da sustentabilidade: as contribuicoes do turismo de base comunitária. Revista de Turismo y Patrimonio Cultural. v. 13, n. 1. p. 57-71. 2015.

Bursztyn, I.; Bartholo, R. O processo de comercialização do turismo de base comunitária no Brasil: desafios, potencialidades e perspectivas. Sustentabilidade em Debate, v.3. n.1, pp.97-116, 2012.

CORIOLANO, L. N. Arranjos produtivos Locais do Turismo Comunitário: atores e cenários em mudanças. Fortaleza: UECE.2009.

COGO, E.L.; DALLABRIDA, V.R. Descentralização e participação social: constatações e análises comparativas em experiências. Anais do Encontro da Associação Nacional de Pós-graduação e Pesquisa em Planejamento Urbano e Regional. Recife-PE, Brasil, 15, 2013.

DEMO, P. Participação é conquista. 5.ed. São Paulo: Cortez, 2001.

EMBRATUR-IEB. Pólos de Ecoturismo - Planejamento e Gestão / Guilherme Wendel de Magalhães (Coord.). São Paulo: TERRAGRAPH, 2001.

GUERRA, A.J.T.; COELHO, M.C.N. (Orgs.). Unidades de Conservação: abordagens e características geográficas. Rio de Janeiro: Bertrand Brasil, $p$. 296, 2009.

GOHN, M.G. Conselhos Gestores e Participação Sociopolítica. São Paulo: Cortez, 2001.

HIWASAKI, L. Community-based tourism: A pathway to sustainability for Japan`s protected areas. Society and Natural Resources, 19: 133-143. 2006

INSTTUTO DE DESENVOLVIMENTO SUSTENTÁVEL E MEIO AMBIENTE DO RIO GRANDE DO NORTE (IDEMA/RN). Plano de manejo da Reserva de Desenvolvimento Sustentável Estadual Ponta do Tubarão (RN): documento síntese. Natal, 2007.

IRVING, M.A. Ecoturismo em áreas protegidas: um desafio no contexto brasileiro. Boletim de Turismo e Administração Hoteleira. São Paulo, n.2, pp.43-55, Centro Universitário lbero-Americano - UNIBERO.2000.

IRVING, M.A. Reinventando a reflexão sobre turismo de base comunitária: inovar é possível? In: BARTHOLO, R.; SANSOLO, D.G.; BURSZTYN, I. (Org.) Turismo de base comunitária: diversidades de olhares e experiências brasileiras. Rio de Janeiro: UFRJ, Letra e Imagem, 2009.

JAFARI, J. The Scientification of Tourism. In: SMITH, V.; BRENT, M. (Orgs.) Hosts and Guests Revisited: Tourism Issues of the 21st Century. New York: Cognizant Communication. pp. 28-41.2001. 
MAGALHÃES, H.; BONONI, V.L.R.; MERCANTE, M.A. Participação da sociedade civil na gestão de unidades de conservação e seus efeitos na melhoria da qualidade ambiental da região Sudeste do Estado do Mato Grosso do Sul. Acta Scientiarum. Human and Social Sciences, Maringá, v.32, n.2, pp.183-192, 2010.

MAX-NEEF. M. La dimension perdida: la inmensidad de la medida humana. Içaria: Barcelona, 2008.

MTUR. Ministério do Turismo. Hábitos de consumo do turismo do brasileiro. Brasilia: Ministério do Turismo, 2009.

MTUR. Ministério do Turismo. Perfil do turista de aventura e do ecoturista no Brasil. Brasilia: Ministério do Turismo, 2010.

OLIVEIRA, M.P.F. A percepção das comunidades da Reserva de Desenvolvimento Sustentável Estadual Ponta do Tubarão, Macau e Guamaré/RN, no contexto da participação popular. 115 f. 2008. Monografia (Graduação em Geografia Universidade Federal do Rio Grande do Norte). Natal, 2008.

ORGANIZAÇÃO INTERNACIONAL TURISMO. Declaração de Otalavo. Otalavo, Equador: OIT, 2001.

ORGANIZAÇÃO INTERNACIONAL TURISMO. Declaração de San José. San José, Costa Rica: OI, 2003.

PAVON, R.G.S. Hacia un Modelo de Aprovechamiento Turistico Sustentable en Areas Naturales Protegidas: Estudio de Caso del Parque Natural Chankanaab de Cozumel. Revista de Turismo y Patrimonio Cultural. Mexico. v.13. n.1, pp.26-42, 2015.

PINTO, R.; CASTRO, L.L.C. Sustentabilidade e turismo comunitário: aspectos teórico-conceituais. Caderno Virtual de Turismo. Rio de Janeiro, v.13, n.2, pp.213-226, 2013.

REDE TUCUM. Rede Cearense de Turismo Comunitário. Presentation held at the II International Seminar on Sustainable Tourism. Fortaleza. 2008.

RIO GRANDE DO NORTE [ESTADO]. Lei no $\mathbf{8 . 3 4 9}$ de julho de 2003. Cria a Reserva de Desenvolvimento Sustentável Estadual Ponta do Tubarão, na região de Diogo Lopes e Barreiras e dá outras providências. Diário Oficial do Estado, Natal, 2003.

SANTOS, M. Técnica, espaço, tempo. São Paulo: Editora Hucitec.1994.

SANTANA TALAVERA, A. Turismo, Empleo y Dependencia Económica. Las Estrategias de las Unidades Domésticas en las Poblaciones Pesqueras (Gran Canaria). Eres, v.2, pp.25-38, 1990.

SANTANA TALAVERA, A. Antropologia do Turismo: Analogias, Encontros e Relações. São Paulo: Aleph, 2009.

TORRAS, M. La participación de los pueblos en su desarrollo. Barcelona: Intermón, 1995. 
UNCTAD/WTO. Modulo de Treinamento para o Sucesso do Turismo Baseado na Comunidade: TBC no Âmbito do PRPE - Programa de Redução da pobreza através da Exportação. Genebra: Internacional Trade Center. 2005.

WWF. Manual de Ecoturismo de Base Comunitária: ferramentas para um planejamento responsável. Brasilia: WWF Brasil. 2003.

\section{Notas:}

1 São diretrizes, princípios norteadores de ação do poder público; regras e procedimentos para as relações entre poder público e sociedade, mediações entre atores da sociedade e do Estado. São, nesse caso, políticas explicitadas, sistematizadas ou formuladas em documentos (Leis, programas, linhas de financiamentos)que orientam ações que normalmente envolvem aplicações de recursos públicos (TEIXEIRA, 2002, p. 2).

${ }^{2} E$ É um lugar onde a sociedade pode participar efetivamente para a prevenção de problemas e soluções das questões socioambientais da região da Unidade (BRASIL, 2007).

${ }^{3}$ Documento técnico mediante o qual, com fundamento nos objetivos gerais de uma unidade de conservação, se estabelece o seu zoneamento e as normas que devem presidir o uso da área e o manejo dos recursos naturais, inclusive a implantação das estruturas físicas necessárias à gestão da unidade. (BRASIL, 2007).

Iracy Wanderley Filha: Universidade Federal do Rio Grande do Norte, Natal, RN, Brasil.

E-mail: ciciea.wf@gmail.com

Link para o currículo Lattes: http://lattes.cnpq.br/5372082985640197

Aída Gisella Veras Mazzolini: Universidade Federal do Rio Grande do Norte, Natal, RN, Brasil.

E-mail: agisella25@gmail.com

Link para o currículo Lattes: http://lattes.cnpq.br/7184499971650824

Francisco Fransualdo de Azevedo: Universidade Federal do Rio Grande do Norte, Natal, RN, Brasil.

E-mail: ffazevedo@gmail.com

Link para o currículo Lattes: http://lattes.cnpq.br/2719998085102847

Data de submissão: 31 de outubro de 2015

Data de recebimento de correções: 24 de abril de 2017

Data do aceite: 24 de abril de 2017

Avaliado anonimamente 